\title{
Anxiety effects on quality of life during the COVID-19 outbreak: A parallel-serial mediation model among nurses in Turkey
}

\author{
Nihan Potas ${ }^{\mathrm{a}, *}$, Nilüfer Koçtürk ${ }^{\mathrm{b}}$ and Şükrü Anıl Toygar ${ }^{\mathrm{c}}$ \\ ${ }^{\mathrm{a}}$ Faculty of Economics and Administrative Sciences, Department of Healthcare Management, Ankara Hact \\ Bayram Veli University, Ankara, Turkey \\ ${ }^{\mathrm{b}}$ Faculty of Education, Department of Educational Science, Hacettepe University, Ankara, Turkey \\ ${ }^{\mathrm{c}}$ Faculty of Applied Sciences, Department of Healthcare Management, Tarsus University, Tarsus-Mersin, Turkey
}

Received 23 October 2020

Accepted 6 January 2021

\begin{abstract}
.
BACKGROUND: Nurses experience loneliness, anxiety, fear, fatigue, sleep disorders, and other physical and mental health problems due to their close contact with patients in cases of epidemic diseases. Among nurses in Turkey, we want to explore how anxiety, psychological health, and social isolation affect nurses' quality of life.

OBJECTIVES: This study aimed to investigate the effects of the COVID-19 pandemic on the quality of life (COVID-19 EQLS), State-Trait Anxiety Inventory (STAI-1 and STAI-2), psychological health, and social isolation among nurses. It also aimed to identify whether the influence of trait anxiety, psychological health, and social isolation are stronger than the direct influence of state anxiety on nurses' quality of life during the pandemic.

METHODS: A cross-sectional study design and STROBE guidelines were implemented. In this study, 638 nurses in Turkey were included using simple random sampling. The participants completed the STAI-1 and STAI-2 and COVID-19 EQLS online-form. The parallel-serial mediation model was used to examine the relationships between the determined variables.

RESULTS: Psychological health, psychological effects of social isolation, and trait anxiety fully mediated the relationship between state anxiety and quality of life of nurses. The total indirect effect of the confidence interval of bootstrapping was statistically different from zero.

CONCLUSIONS: Trait anxiety, psychological health, and social isolation were the main factors with statistically significant indirect effects on the quality of life of Turkish nurses in this study.
\end{abstract}

Keywords: Anxiety, trait anxiety, social isolation, psychological health, pandemic

\section{Introduction}

The 2019 coronavirus disease (COVID-19) outbreak that began in China has become a threat to global health [1], with a significant number of infected

\footnotetext{
${ }^{1}$ Orcid ID: https://orcid.org/0000-0002-0393-3135

${ }^{2}$ Orcid ID: https://orcid.org/0000-0001-6124-1842

${ }^{3}$ Orcid ID: https://orcid.org/0000-0002-3444-3243

*Address for correspondence: Nihan Potas, Faculty of Economics and Administrative Sciences, Department of Healthcare Management, Ankara HacıBayram Veli University, Ankara, Turkey. E-mail: nihan_potas@hotmail.com.
}

patients and associated deaths [2]. The World Health Organization (WHO) declared the COVID-19 outbreak as a public health emergency of international concern on March, 11 [3, 4].

During the pandemic process, while many professions continued their working life in the home environment, certain professions worked much more intensely than before the pandemic [5-7]. One of these professions is nurses. The nursing profession, which has a key role in the effective and efficient delivery of health services, aims to help people who cannot meet their basic needs [8]. With the care 
services they offer, nurses help patients gain a minimum level of resistance to the diseases they suffer, feel better, and increase their hopes that they will recover [9]. Thus, nursing has a very valuable function in terms of public health.

In epidemic events that threaten public health, the duties and responsibilities of nurses become more important. Nurses have a duty to provide care using appropriate safety measures in the event of natural or man-made disasters, including infectious disease outbreaks [10]. Research shows that nurses sacrifice their own needs during sudden natural disasters and infectious diseases, showing exceptional ethical commitment and professional responsibility [11]. However, nurses' working schedules and working conditions became more demanding related burdens and increased stress due to their role in combatting the pandemic [5, 12-14]. With the intensity of workload, due to the difficult circumstances imposed by the COVID-19 pandemic, nurses have had to put their own lives and the lives of their loved ones at risk while treating patients who were diagnosed with COVID-19. The risk of infection and death posed by COVID-19 causes significant psychosocial stress in nurses and other healthcare professionals [15]. Because of the high risk, nurses faced stringent social isolation, becoming separated from their friends and relatives and, in some cases, even their own children [16]. Shanafelt et al. found that nurses, like other healthcare professionals, were most concerned about access to childcare during increased work hours and school closures, and support for other personal and family needs as work hours and demands, Considering this fact, the World Health Organization [17] made very important suggestions for nurses and other healthcare professionals regarding mental health and psychosocial issues. For example, World Health Organization [17] states that mental health and psychosocial health are as important as physical health, and their protection is essential. Moreover, unless necessary, physical contact with the family and social environment should be avoided and digital communication should be used instead. In summary, these changes in the work and social life of nurses are likely to affect their anxiety levels and quality of life.

When the literature on the effect of previous epidemics is examined, findings can support its detrimental effect on mental health. For example, Lau et al. [18] found that low or moderate-to-severe post-traumatic stress symptoms were reported during the 2002-2004 SARS epidemic; and that female nurses were at higher risk of developing SARS epidemic-related post-traumatic stress symptoms. Similarly, in studies during the COVID-19 pandemic process, it is emphasized that nurses are at risk in terms of mental health problems [5, 12-14, 19]. Recent research has found that experiences with SARS and COVID-19 pandemics are similar, showing that nurses experience anxiety, stress, and fear [20]. In a study conducted in Korea, it was found that nurses had significantly higher levels of depression, general anxiety, and virus-related anxiety symptoms [12]. However, contrary to expectations, single nurses reported more severe depressive symptoms than married nurses $(20.3 \%$ vs $14.1 \%)$, and junior nurses $(<40$ years old) reported more anxiety about the COVID19 pandemic. In addition, these studies reported that age, sex, and work duration were significantly associated with depression. Similarly, in a study conducted in China [5], while results show that nurses are at risk for experiencing anxiety and depression, the demographic background (e.g., the family responsibilities and burdens), psychosocial factors, and work-related factors predicted the psychological responses of nurses. However, nurses who chose not to take leave from work or who did not avoid going to work during pandemic were less anxious and depressed [5]. The conflicting findings among the studies also suggest that there may be different factors affecting the relationship between the effect of COVID-19 pandemic and the anxiety level of nurses.

In the evidence-based literature, anxiety is evaluated in two different ways as state anxiety (STAI-1) and trait anxiety (STAI-2). STAI-1 can be defined as the arousal of the autonomic nervous system induced by different events perceived as threats. This type of anxiety indicates how a person feels when they perceive a threat; it is considered a temporary reaction [21]. However, STAI-2 is defined as the general tendency of an individual to be upset in stressful situations, or as the mean level of anxiety over a longer period [22, 23]. Because of its temporary quality, the direct influence of STAI-1 can be weaker than the influence of psychological health on nurses' quality of life. As a matter of fact, previous studies emphasize that there is a relationship between STAI-1 and the patients' quality of life [24, 25]. Although some have assessed nurses' job satisfaction [26], studies on quality of life are most often focused on patients.

As COVID-19 affects psychological health, these psychological effects can also affect STAI-2 levels. Thus, the impact of STAI-2 on quality of life might be higher than we anticipated [27]. Additionally, the effect of COVID-19 on nurses' quality of life 
can make their lives more difficult due to increased STAI-2 and social isolation, and reduced psychological health $[28,29]$. In the literature, it is emphasized that high STAI-2 can cause STAI-1 [30]. However, it is not known whether psychological health, the psychological effect of social isolation, and STAI2 mediate the relationship between nurses' STAI-1 and influence quality of life.

As a result, psychological health influences quality of life [31] and because of the multiple threats to nurses' mental health, it is of great importance to assess the quality of life of nurses to implement the appropriate measures as soon as possible. However, in the literature, it is seen that some studies on the anxiety levels of nurses have been conducted with a limited sample and samples with different cultural characteristics, and there is not enough information about the anxiety levels of nurses [14]. As far as we know, there are no studies about the effect of pandemic on the nurses' quality of life in Turkey. For these reasons, in the present study, we aimed to investigate the effects of the COVID-19 pandemic on quality of life, state /trait anxiety, psychological health, and social isolation within nurses. Another aim was to determine whether the influences of trait anxiety, psychological health, and social isolation are stronger than the direct influence of state anxiety on the nurses' quality of life (EQLS) during the COVID-19 pandemic. For this purpose, relevant literature was reviewed, and our hypotheses were formulated and presented according to the model in Fig. 1:

$H_{1}$ : STAI-1 influences nurses' EQLS scores.

$\mathrm{H}_{2}$ : Psychological health mediates the relationship between STAI-1 and nurses' COVID-19 EQLS scores.

$H_{1 a}$ : STAI-1 influences the psychological health of nurses.
$H_{1 b}$ : Psychological health influences nurses' COVID-19 EQLS scores.

$H_{3}$ : The psychological effect of social isolation mediates the relationship between STAI-1 and nurses' COVID-19 EQLS scores.

$H_{3 a}$ : STAI-1 influences the psychological effect of nurses' social isolation.

$H_{3 b}$ : The psychological effect of social isolation influences nurses' COVID-19 EQLS.

$H_{4}$ : Psychological health, the psychological effect of social isolation, and STAI-2 mediate the relationship between STAI-1 and nurses' EQLS.

$H_{4 a}$ : STAI-1, psychological health, and the psychological effect of social isolation influence nurses' STAI-2 of during the COVID-19 pandemic.

$H_{4 b}$ : STAI-2, psychological health, and the psychological effect of social isolation influence nurses' EQLS.

$H_{5 a}$ : Psychological health influences nurses' STAI-2.

$H_{5 b}$ : The psychological effect of social isolation influences nurses' STAI-2.

\section{Methods}

\subsection{Study setting, data collection, and design}

As of 2020, according to the Ministry of Health, 198,465 nurses are working actively in Turkey [32]. The sample size was determined to be 599 with a $4 \%$ margin of error by using the simple random sampling method. After ethics committee approval (AHBV Unv. -2020/117), Google online surveys were sent to nurses from April 30 through May 30, 2020. Due to the intensive working hours of nurses during the COVID-19 pandemic, additional online surveys were sent beyond the determined sampling size. Thus,

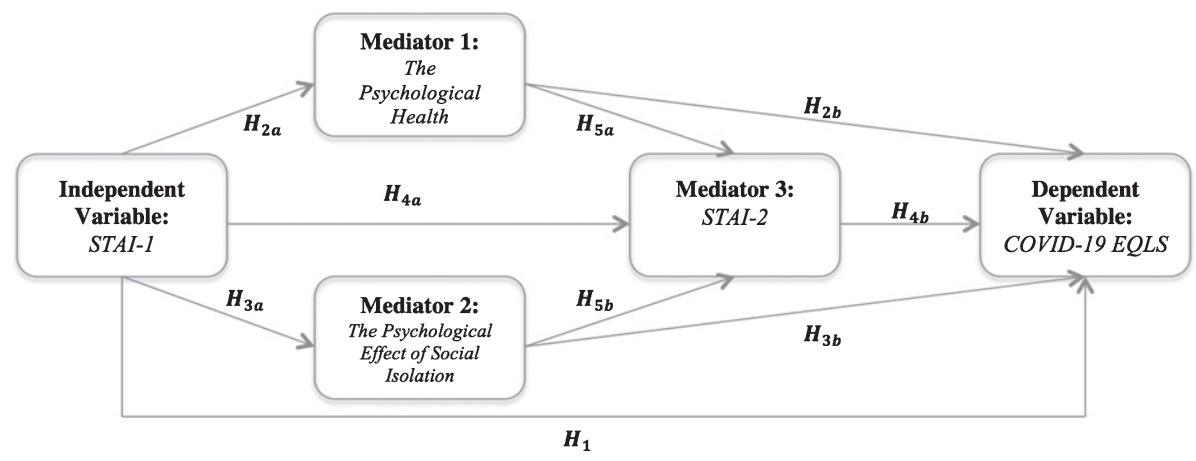

Fig. 1. Hypothesized model. 
responses of the online survey were about 654 , which was more than the determined sample size. Some participants did not fully complete the online survey. After the specified number of participants had been reached, 16 of the online surveys were eliminated. In this study, $9.4 \%$ of participants were male nurses. The participants' mean age was $32.20 \pm 10.689$. This study followed STROBE reporting guidelines to ensure accuracy, transparency of results, and quality of observational research [33].

\subsection{Measurement tools}

Personal Information Form. Participants were asked to indicate their age, gender, and to respond the following two questions:

1. Do you think that the COVID-19 pandemic has influenced your psychological health? (0 "No" - 10 "Absolutely")

2. Do you think that social isolation because of the pandemic has influenced your psychological well-being? (0 "No" - 10 "Absolutely")

State-Trait Anxiety Inventory (STAI-1 and STAI-2). STAI-1 includes 20 items to measure state anxiety [34]. The intensity of emotions or behaviors is measured in the State Anxiety Inventory (STAI-1) as: (1) very low; (2) somewhat low; (3) moderate; and (4) very intense. In addition, STAI-2 has 20 items in the Trait Anxiety Inventory (STAI-2), items to measure the frequency of emotions or behaviors in the following scale: (1) almost never, (2) sometimes, (3) often, and (4) almost always. Trait anxiety was measured at baseline, and state anxiety was examined during the pandemic period (follow-up). High concurrent validity was found between the State-Trait Anxiety Inventory and different scales that measure anxiety, with correlation ranging from 0.73 to 0.85 [35]. STAI inventory scores are classified as 20-37: no or low anxiety, 38-44: moderate anxiety, and 45-80: high anxiety. Öner and LeCompte [36] have been adopted the validity and reliability of the STAI to the Turkish version. The inventory retained its original form. In this research, the Turkish version of the STAI was used. STAI-1's Cronbach's alpha was .90, and the STAI-2 Cronbach's alpha was .84.

COVID-19 Pandemic's Effect on Quality of Life Scale (COVID-19 EQLS). The COVID-19 Pandemic's Effect on Quality of Life Scale (COVID-19 EQLS) was developed by Erçetin, Potas, Açıkalın, and Çevik, who also assessed its validity and reliability [37]. The scale has 29 items divided into four sub-dimensions: psychological (13-items), social (4items), professional (4-items), and familial effects (8-items). The scale measures the effects of the COVID-19 pandemic using a four-point scale. The levels are (1) "I am affected at a very low degree," (2) "I am affected at a low degree," (3) "I am affected," and (4) "I am affected at a very high degree." The COVID-19 EQLS score classification is the following, 29-51.99: no or low effect, 52-72.99: moderate effect, and 73-116: high effect. In this research, according to the participant responses, the Quality of Life Scale's Cronbach's alpha was.85.

\subsection{Statistical analysis}

For descriptive statistics, the central tendencies and distributions of the variables are given. The coefficient of correlation was used to test the relationship between each variable. A parallel-serial mediation model was used to test the three mediators (psychological health, the psychological effect of social isolation, and STAI-2). The parallel-serial mediation model was set up, as shown in Fig. 1. Three mediators were involved in the model: psychological health (M1), the psychological effect of social isolation (M2), and STAI-2 (M3). In this study, M1, M2, and M3 mediate the relationship between an independent variable "STAI-1 (X)" and the dependent variable "COVID-19 EQLS (Y)". The paths were analyzed using multiple regression. According to the multiple regression assumptions perceptive, all of them were checked: the linear relationship between the independent and dependent variables, the mean of residuals was zero, normality of residuals, no multicollinearity, no autocorrelation of residuals and homoscedasticity of residuals, or equal variance. Additionally, 0.05 as the level of error probabilities ( $p$-value) was used. Statistical analyses were performed using $\mathrm{R}$ version 3.5.3, SPSS version 23.0.

\section{Results}

The results showed that psychological health was affected by social isolation $(7.70 \pm 2.562)$ and $\mathrm{CO}$ VID-19 affected their psychological health $(7.97 \pm$ 2.501). The results of the COVID-19 EQLS score showed that nurses were highly affected (78.22 \pm 9.931). The nurses had high anxiety, as shown by the STAI-1 (54.46 \pm 11.498$)$ and STAI-2 (48.76 \pm 7.475) results.

From Table 1, the correlation between gender, age, and the effect of COVID-19 on psychological 
Table 1

Mean standard deviation correlations among variables $(n=638)$

\begin{tabular}{|c|c|c|c|c|c|c|c|c|c|}
\hline Variables & $\bar{x}$ & $s$ & 1 & 2 & 3 & 4 & 5 & 6 & 7 \\
\hline 1. Gender & 1.91 & 0.292 & 1 & & & & & & \\
\hline 2. Age & 32.20 & 10.689 & $0.281^{* *}$ & 1 & & & & & \\
\hline $\begin{array}{l}\text { 3. Psychological effect } \\
\text { of social isolation }\end{array}$ & 7.70 & 2.562 & $0.336^{* *}$ & $0.490^{* *}$ & 1 & & & & \\
\hline 4. Psychological health & 7.97 & 2.501 & $0.400^{* *}$ & $0.428^{* *}$ & $0.872^{* *}$ & 1 & & & \\
\hline 5. COVID-19 EQLS & 78.22 & 9.931 & $0.145^{* *}$ & $0.155^{* *}$ & $0.476^{* *}$ & $0.536^{* *}$ & 1 & & \\
\hline 6. STAI-1 & 54.46 & 11.498 & -0.028 & $-0.078^{*}$ & 0.052 & 0.072 & 0.076 & 1 & \\
\hline 7. STAI-2 & 48.76 & 7.475 & 0.001 & $-0.365^{* *}$ & $0.182^{* *}$ & $0.078^{*}$ & $0.339^{* *}$ & $0.131^{* *}$ & 1 \\
\hline
\end{tabular}

${ }^{*} p<0.05,{ }^{* *} p<0.01$; STAI: State-Trait Anxiety Inventory; COVID-19 EQLS: COVID-19 Pandemic's Effect on Quality of Life Scale.

health, the psychological effect of social isolation, STAI-1, STAI-2, and COVID-19 EQLS are shown. Overall, the effect of COVID-19 on psychological health and COVID-19 EQLS have significant positive correlations $(p<0.01)$ and high associations. The psychological effect of social isolation-gender, the effect of COVID-19 on psychological health, the psychological effect of social isolation-age, the effect of COVID-19 on psychological health, and the psychological effect of social isolation- COVID-19 EQLS and STAI-2-COVID-19 EQLS have significant correlations $(p<0.01)$ that are positive and moderate. Age- STAI-2 has significant, negative, and low associations.

The first mediator (M1) was tested using mediation analysis. STAI-1 (X) influences COVID-19 EQLS (Y). Model $1(F=9.500, d f=3 ; 634, p<0.01)$ and the coefficient of gender, age, and STAI- $1(\beta=0.077$, $p<0.01)$ were statistically significant. This confirmed $H_{1}$.

STAI-1 (X) influences psychological health (M1). Model $1(F=82.058, d f=3 ; 634, p<0.01)$ and the coefficient of gender, age, and STAI- $1(\beta=0.023$, $p<0.01)$ were statistically significant. This supported $\mathrm{H}_{2 a}$. Psychological health (M1) influenced COVID19 EQLS (Y). The model $(F=89.860, d f=3 ; 634, p<$ $\left.0.01, R^{2}=0.298\right)$ and the coefficient of gender $(\beta=$ $-2.463, p<0.05)$, age $(\beta=-0.076, p<0.05)$, and psychological health $(\beta=2.382, p<0.01)$ were statistically significant. This supported $H_{2 b}$. STAI-1 (X), psychological health (M1) influenced COVID-19 EQLS (Y). The coefficient of age and psychological health were statistically significant; conversely, the coefficient of STAI-1 was not statistically significant ( $\beta=0.022, p=0.447)$, and model 2 was statistically significant $(F=67.495, d f=4 ; 633, p<0.01)$. Thus, $\mathrm{H}_{2}$ was supported.

The second mediator (M2) was tested using mediation analysis. STAI-1 (X) influenced effect of social isolation (M2). Model $1 \quad(F=86.747, d f=3 ; 634$, $p<0.01)$ and the coefficients of gender, age, and STAI-1 $(\beta=0.020, p<0.01)$ were statistically significant. Thus, hypothesis $H_{3 a}$ was supported. Effect of social isolation (M2) influenced COVID-19 EQLS (Y). The model $(F=64.654, d f=3 ; 634, p<0.01$ $\left.R^{2}=0.234\right)$ and the coefficient of age $(\beta=-0.095$, $p<0.05)$ and the effect of social isolation $(\beta=2.043$, $p<0.01)$ were statistically significant. Thus, $H_{3 b}$ was also supported. STAI-1 (X), effect of social isolation (M2) influenced COVID-19 EQLS (Y). The coefficients of age and psychological health were statistically significant; conversely, the coefficient of STAI-1 was not statistically significant $(\beta=0.036$, $p=0.234$ ), and model 3 was statistically significant $(F=48.876, d f=4 ; 633, p<0.01)$. Thus, $H_{3}$ was supported.

Psychological health (M1) influenced STAI-2 (M3). The model $(F=36.761, d f=3 ; 634, p<0.01)$ and the coefficient of psychological health $(\beta=0.189$, $p=0.140$ ) were not statistically significant. This did not support $H_{5 a}$. Effect of social isolation (M2) influenced STAI-2 (M3). The model $(F=36.168$, $d f=3 ; 634, p<0.01)$ and the coefficient of the effect of social isolation ( $\beta=0.103, p=0.415)$ were statistically significant. This did not support $H_{5 b}$ either.

The third mediator (M3) was tested using parallelseries mediation analysis. STAI-1 (X), psychological health (M1), and effect of social isolation (M2) influenced STAI-2 (M3). Model 1 ( $F=27.001, d f=5 ; 632$, $p<0.01)$ and the coefficients of gender, age, STAI-1, psychological health, and the effect of social isolation were statistically significant. This supported $H_{4 a}$. Psychological health (M1), effect of social isolation (M2), and STAI-2 (M3) influenced COVID-19 EQLS (Y). The model $(F=105.929, d f=5 ; 632, p<0.01$; $\left.R^{2}=0.456\right)$ and the coefficient of gender $(\beta=-3.606$; $p<0.01)$, psychological health $(\beta=1.621 ; p<0.01)$, the effect of social isolation $(\beta=0.773 ; p<0.01)$, and STAI-2 $(\beta=0.575 ; p<0.01)$ were statistically significant. This supported $H_{4 b}$. STAI-1 (X), 
Table 2

Results of mediation analysis and parallel-series mediation analysis

\begin{tabular}{|c|c|c|c|c|c|c|c|}
\hline & \multicolumn{7}{|c|}{ Dependent variables } \\
\hline & \multirow{2}{*}{$\begin{array}{c}\text { M1: } \\
\text { Pychological } \\
\text { health } \\
\text { Model } 1 \\
\end{array}$} & \multirow{2}{*}{$\begin{array}{c}\text { M2: } \\
\text { Effect of } \\
\text { social isolation } \\
\text { Model } 1\end{array}$} & \multirow{2}{*}{$\begin{array}{c}\text { M3: } \\
\text { STAI-2 } \\
\text { Model } 1 \\
\end{array}$} & \multicolumn{4}{|c|}{$\begin{array}{c}\mathrm{Y}: \\
\text { COVID-19 EQLS }\end{array}$} \\
\hline & & & & Model 1 & Model 2 & Model 3 & Model 4 \\
\hline \multicolumn{8}{|l|}{ Step 1: Control variables } \\
\hline Gender & $2.603^{* *}(0.301)$ & $1.891^{* *}(0.306)$ & $2.270^{*}(1.021)$ & $3.753^{* *}(1.377)$ & $-2.419(1.247)$ & $-0.070(1.268)$ & $-3.642 * *(1.107)$ \\
\hline Age & $0.082^{* *}(0.008)$ & $0.105^{* *}(0.008)$ & $-0.254^{* *}(0.029)$ & $0.121^{* *}(0.038)$ & $-0.073^{*}(0.035)$ & $-0.090^{*}(0.038)$ & $0.064(0.034)$ \\
\hline \multicolumn{8}{|l|}{ Step 2: Mediator 1} \\
\hline M1: Psychological health & & & $0.853^{* *}(0.227)$ & & $2.367^{* *}(0.156)$ & & $1.628^{* *}(0.248)$ \\
\hline \multicolumn{8}{|l|}{ Step 3: Mediator 2} \\
\hline M2: Effect of social isolation & & & $0.839^{* *}(0.224)$ & & & $2.022^{* *}(0.160)$ & $0.776^{* *}(0.244)$ \\
\hline $\begin{array}{l}\text { Step 4: Mediator } 3 \\
\text { M3: STAI-2 }\end{array}$ & & & & & & & $0.578^{* *}(0.043)$ \\
\hline \multicolumn{8}{|l|}{ Step 5: Independent variable } \\
\hline X: STAI-1 & $0.023^{* *}(0.007)$ & $0.020^{* *}(0.007)$ & $0.065^{* *}(0.024)$ & $0.077^{*}(0.034)$ & $0.022(0.029)$ & $0.036(0.030)$ & $0.016(0.026)$ \\
\hline Constant & $-0.796(0.685)$ & $-0.282(0.697)$ & $44.086^{* *}(2.199)$ & $58.334^{* *}(3.137)$ & $60.219^{* *}(2.690)$ & $58.904^{* *}(2.806)$ & $34.620^{* *}(3.037)$ \\
\hline$R^{2}$ & 0.280 & 0.291 & 0.176 & 0.043 & 0.299 & 0.236 & 0.456 \\
\hline$F$ Statistic & $\begin{array}{c}82.058^{* *} \\
(d f=3 ; 634)\end{array}$ & $\begin{array}{c}86.747^{* *} \\
(d f=3 ; 634)\end{array}$ & $\begin{array}{c}27.001^{* *} \\
(d f=5 ; 632)\end{array}$ & $\begin{array}{c}9.500^{* *} \\
(d f=3 ; 634)\end{array}$ & $\begin{array}{c}67.495^{* *} \\
(d f=4 ; 633)\end{array}$ & $\begin{array}{c}48.876^{* *} \\
(d f=4 ; 633)\end{array}$ & $\begin{array}{c}88.246^{* *} \\
(d f=6 ; 631)\end{array}$ \\
\hline
\end{tabular}

${ }^{*} p<0.05,{ }^{* *} p<0.01$; STAI: State-Trait Anxiety Inventory; COVID-19 EQLS: COVID-19 Pandemic's Effect on Quality of Life Scale. 
psychological health (M1), effect of social isolation (M2), and STAI-2 (M3) influenced COVID-19 EQLS (Y). Model $4(F=88.246, d f=6 ; 631, p<0.01)$ and the coefficients of gender, psychological health, the effect of social isolation, and STAI-2 were statistically significant. Conversely, the coefficient of STAI-1 was not statistically significant $(\beta=0.016$, $p=0.546$ ). Thus, $H_{4}$ was supported.

Results of the mediation and parallel-series mediation analysis showed that three conditions were met, and full mediation was supported in three analyses. In the parallel-series mediation analysis, the direct effect was not significant (effect $=.016 ; t=0.604, p=$ 0.546). The indirect effect of the independent variable on the dependent variable through the three-mediator variables was significant. The total indirect effect of the confidence interval of bootstrapping is excluding the zero (bootstrap sample size $=10^{4}$ ). This means that the total indirect effect is statistically different from zero. If each indirect effect is examined, the indirect effect of (STAI-1 $\rightarrow$ psychological health $\rightarrow$ COVID-19 EQLS, STAI-1 $\rightarrow$ social isolation $\rightarrow$ COVID-19EQLS, STAI- $\rightarrow$ STAI-2 $\rightarrow$ COVID19EQLS, STAI-1 $\rightarrow$ psychological health $\rightarrow$ STAI-2 $\rightarrow$ COVID-19 EQLS, and STAI- $1 \rightarrow$ social isolation $\rightarrow$ STAI-2 $\rightarrow$ COVID-19 EQLS) confidence interval of the bootstrapping are excluding the zero.

\section{Conclusions}

The COVID-19 pandemic can affect physical health, mental health, and quality of life. The main objective of combating the pandemic is safeguarding everyone's health. However, it is unlikely that this objective can be achieved by ignoring nurses' physical health, mental health, and quality of life. Therefore, this study focused on nurses' anxieties and quality of life.

This study showed that nurses' EQLS was highly affected by COVID-19 (78.22 \pm 9.931$)$, their STAI-1 levels $(54.46 \pm 11.498)$, and their STAI2 levels were high $(48.76 \pm 7.475)$. According to nurses' answers, their psychological condition was affected by social isolation $(7.70 \pm 2.562)$ and COVID-19 pandemic affected their psychological health $(7.97 \pm 2.501)$. As expected, STAI-1 of nurses influenced their COVID-19 EQLS scores $(\beta=0.077, p<0.01)$. Nurses' STAI-1 influenced their psychological health $(\beta=0.023, p<0.01)$. In addition, their psychological health influenced
COVID-19 EQLS scores $(\beta=2.382, p<0.01)$. The influence of nurses' psychological health was stronger than the direct influence of STAI-1 on their quality of life during the COVID-19 pandemic. Since STAI-1 is temporary [30], the effect of COVID-19 on psychological health has broken the influence of temporary anxiety. Nurses' STAI-1 influences social isolation $(\beta=0.020, p<0.01)$. In addition, social isolation influenced COVID-19 EQLS score $(\beta=2.043, p<0.01)$. The influence of social isolation was stronger than the direct influence of STAI-1 on the quality of life of nurses during the COVID19 pandemic. Regardless of their profession, human beings are inherently social [38], thus, quality of life was directly affected due to the implementation of extraordinary measures to combat the spread of the disease, such as social isolation, social distancing, and curfew. However, considering the service area of nurses, the effectiveness of social isolation may be due to this.

Nurses' STAI-1, psychological health, and the effect of social isolation influenced STAI-2. Nurses' psychological health, social isolation, and STAI-2 influenced COVID-19 EQLS score. Psychological health, psychological effects of social isolation, and STAI-2 mediated the relationship between STAI-1 and COVID-19 EQLS score. The indirect effect of the confidence interval of bootstrapping was statistically different from zero. As mentioned before, the high level of temporary anxiety experienced by the nurses led to the strengthening of STAI-2. This strength came directly from STAI-1. Results showed that psychological health and social isolation had no effect on STAI-2. This demonstrated that STAI-2, psychological health, and social isolation affected quality of life more strongly. Considering that STAI-1 is associated with personality traits [39] and personality is a structure resistant to change [40,41], this result was expected. On the other hand, the reason for this situation may be that the nurses in this study did not experience pathological anxiety due to pandemic. However, new causal studies are needed to reach a definitive opinion.

This study had some limitations. First, given the time sensitivity of the pandemic outbreak, it is limited to the chosen method and sampling techniques. Therefore, the study was based on an online survey, and we were unable to evaluate participants face-toface because of pandemic restrictions. In addition, the reported anxiety levels and pandemic effect is based on the participants' own statements, and this may not be consistent with an assessment by mental 
health professionals. Despite these limitations, during the pandemic period, much valuable information has been obtained. To the best of our knowledge, this is the first study in Turkey to report the nurses' quality of life and nurses' state/trait anxiety during the COVID-19 pandemic. Results of this study show that improving nurses' quality of life, protecting their physical and mental health, and ensuring efficient functioning should be a priority in the fight against COVID-19 pandemic. Minimizing nurses' concerns about their families' health and daily life will increase their efficiency and might protect them from significant mental health problems later on. In the light of this information, psychological support may be offered to nurses for job stress [42] and a content of psychological support can be created in these subjects. For example, to reduce problems such as post-traumatic stress, depression, and anxiety disorders among nurses, programs should be implemented to protect their quality of life and mental health. Applications for mental support based on specific needs should be generated and supported by colleagues and hospital managers. In addition, as organization factors (e.g., supervisor support, teamwork, staffing work regulation, salary and organizational policies) are the effective factors on nurses' work ability, health care leaders may increase the quality of support of management and supervisors [43]. Nurses should be regularly allowed to communicate with their families remotely to cope with the stress of their profession. In addition, the impact of the pandemic on nurses' quality of life can be reduced by lowering their anxiety levels. In addition to these, authorities could consider setting up mental health teams to deal with psycho-social issues and provide psychological support to nurses through hospital-based psychoeducation programs and strategies. Moreover, nurses with high levels of anxiety can be identified with regular screenings, and individual psychotherapy and so on. services can be provided them. Lastly, because social isolation affects quality of life more strongly than STAI-1, it may be suggested to use different methods (e.g., digital communication; [17] to reduce the effect of social isolation.

The results of this study have the potential to help healthcare workers, hospital management, governmental organizations, and decision-makers to protect nurses' physical and mental health. We also recommend monitoring nurses for symptoms of anxiety.

In the present study, both symptoms of state anxiety and symptoms of trait anxiety were found. Our results showed that state anxiety had a less direct effect on nurses' quality of life. Conversely, our study showed that trait anxiety, psychological health, and the effect of social isolation negatively affected quality of life.

\section{Conflict of interest}

None of the authors have any conflicts of interest to report.

\section{Funding}

This research did not receive any specific grant from funding agencies in the public, commercial, or not-for-profit sectors.

\section{References}

[1] Wang C, Horby PW, Hayden FG, Gao GF. A novel coronavirus outbreak of global health concern. Lancet. 2020;395(10223). https://doi.org/10.1016/S0140-6736(20) 30185-9.

[2] Nishiura H, Jung S, Linton NM, Kinoshita R, Yang Y, Hayashi K, et al. The Extent of Transmission of Novel Coronavirus in Wuhan, China, 2020. J Clin Med. 2020;9(2):330. https://doi.org/10.3390/jcm9020330.

[3] Cucinotta D, Vanelli M. WHO declares COVID-19 a pandemic. Acta Biomed. 2020;91(1):157-60. https:// doi.org/10.23750/abm.v91i1.9397.

[4] Mahase E. China coronavirus: WHO declares international emergency as death toll exceeds 200. BMJ. 2020;368:m408. https://doi.org/10.1136/bmj.m408.

[5] Han L, Wong FKY, She DLM, Li SY, Yang YF, Jiang MY, et al. Anxiety and Depression of Nurses in a North West Province in China During the Period of Novel Coronavirus Pneumonia Outbreak. J Nurs Scholarsh. 2020;52(5):564-73. https://doi.org/10.1111/jnu.12590.

[6] Shanafelt T, Ripp J, Trockel M. Understanding and Addressing Sources of Anxiety among Health Care Professionals during the COVID-19 Pandemic. JAMA - J Am Med Assoc. 2020;323(21):2133-4. https://doi.org/10. 1001/jama.2020.5893.

[7] Williamson V, Murphy D, Greenberg N. COVID-19 and experiences of moral injury in front-line key workers. Occup Med (Lond). 2020;70(5):317-9. https://doi.org/ 10.1093/occmed/kqaa052.

[8] Ünsal A. Hemşireliğin dört temel kavrami : İnsan, çevre, sağlık ve hastalık, hemşirelik. Ahi Evran Üniversitesi Sağlık Bilim Derg. 2017;1:11-25.

[9] Warelow P, Edward KL, Vinek J. Care: What nurses say and what nurses do. Holist Nurs Pract. 2008;22(3):146-53. https://doi.org/10.1097/01.HNP.0000318023.53151.33.

[10] Canadian Nurses Association. Ethics in Practice for Registered Nurses. 2008;15:54-60.

[11] Aliakbari F, Hammad K, Bahrami M, Aein F. Ethical and legal challenges associated with disaster nursing. Nurs Ethics. 2015;22(4):493-503. https://doi.org/10.1177/ 0969733014534877.

[12] Ahn MH, Shin YW, Kim JH, Kim HJ, Lee K-U, Chung S. High Work-related Stress and Anxiety Response to COVID- 
19 among Healthcare Workers in South Korea: SAVE study. 2020. https://doi.org/10.31234/osf.io/9nxth.

[13] Lu W, Wang H, Lin Y, Li L. Psychological status of medical workforce during the COVID-19 pandemic: A cross-sectional study. Psychiatry Res. 2020;288:112936. https://doi.org/10.1016/j.psychres.2020.112936.

[14] Nemati M, Ebrahimi B, Nemati F. Assessment of iranian nurses' knowledge and anxiety toward covid-19 during the current outbreak in iran. Arch Clin Infect Dis. 2020. https://doi.org/10.5812/archcid.102848.

[15] Huang L, Lin G, Tang L, Yu L, Zhou Z. Special attention to nurses' protection during the COVID-19 epidemic. Crit Care. 2020;24:10-2. https://doi.org/10.1186/s13054020-2841-7.

[16] Usher K, Bhullar N, Jackson D. Life in the pandemic: Social isolation and mental health. J Clin Nurs. 2020;29(1516):2756-57. https://doi.org/10.1111/jocn.15290.

[17] World Health Organization. Covid-19 salgını sirasında ruh sağlı̆̆ıve psikososyal konular. 2020:1-6.

[18] Lau JTF, Yang X, Pang E, Tsui HY, Wong E, Yun KW. SARS-related perceptions in Hong Kong. Emerg Infect Dis. 2005;11(3):417-24. https://doi.org/10.3201/eid1103.040 675.

[19] Doshi D, Karunakar P, Sukhabogi JR, Prasanna JS, Mahajan SV. Assessing Coronavirus Fear in Indian Population Using the Fear of COVID-19 Scale. Int J Ment Health Addict. 2020;23(4):510-4. https://doi.org/10.1007/s11469020-00332-x.

[20] Tercan M, Bozkurt FT, Patmano G, Saraçoğlu G, Gür SC. Anxiety and Depression Differences Between the Nurses Working at a COVID-19 Pandemic Hospital. Med Sci Discov. 2020;7(6):526-31. https://doi.org/10.36472/ msd.v7i6.389.

[21] Spielberger CD, Sydeman SJ. State-trait anxiety inventory and state-trait anger expression inventory. use Psychol. Test. Treat. Plan. outcome Assess., 1994.

[22] Demyttenaere K, Nijs P, Evers-Kiebooms G, Koninckx PR. The effect of a specific emotional stressor on prolactin, cortisol, and testosterone concentrations in women varies with their trait anxiety. Fertil Steril. 1989;52(6):9428. https://doi.org/10.1016/S0015-0282(16)53156-2.

[23] Endler NS, Parker JDA, Bagby RM, Cox BJ. Multidimensionality of State and Trait Anxiety: Factor Structure of the Endler Multidimensional Anxiety Scales. J Pers Soc Psychol. 1991;60(6):919-26. https://doi.org/10.1037/00223514.60.6.919.

[24] Dragomir BI, Fodoreanu L. Correlations between state anxiety and quality of life in metastatic breast cancer patients. Rev Medico-Chir a Soc Med Nat Din Iasi. 2013;117(3): 610-5.

[25] Aggelopoulpou Z, Fotos NV, Chatziefstratiou AA, Giakoumidakis K, Elefsiniotis I, Brokalaki $\mathrm{H}$. The level of anxiety, depression and quality of life among patients with heart failure in Greece. Appl Nurs Res. 2017;34:52-6. https://doi.org/10.1016/j.apnr.2017.01.003.

[26] Cimete G, Gencalp NS, Keskin G. Quality of Life and Job Satisfaction of Nurses. J Nurs Care Qual. 2003;18(2):151-8. https://doi.org/10.1097/00001786-200304000-00009.

[27] Taoka R, Matsunaga H, Kubo T, Suzuki T, Yamamoto $\mathrm{S}$. Impact of trait anxiety on psychological well-being in men with prostate cancer. Int Braz J Urol. 2014;40(5): 620-6. https://doi.org/10.1590/S1677-5538.IBJU.2014.05. 06.

[28] Sun N, Wei L, Shi S, Jiao D, Song R, Ma L, et al. A qualitative study on the psychological experience of caregivers of
COVID-19 patients. Am J Infect Control. 2020;48(6):592-8. https://doi.org/10.1016/j.ajic.2020.03.018.

[29] Liu Q, Luo D, Haase JE, Guo Q, Wang XQ, Liu S, et al. The experiences of health-care providers during the COVID-19 crisis in China: a qualitative study. Lancet Glob Heal. 20208(6):e790-e798. https://doi.org/10.1016/S2214109X(20)30204-7.

[30] Brymer E, Freeman E, Richardson M. Editorial: One health: The well-being impacts of human-nature relationships. Front Psychol. 2019;10:1611. https://doi.org/10.3389/fp syg.2019.01611.

[31] Zhang Y, Ma ZF. Impact of the COVID-19 pandemic on mental health and quality of life among local residents in Liaoning Province, China: A cross-sectional study. Int J Environ Res Public Health. 2020;17(7):2381. https://doi. org/10.3390/ijerph17072381.

[32] Ministry of Health. 7-22769sgc.pdf 2020. https://www2. tbmm.gov.tr/d27/7/7-22769sgc.pdf (accessed May 11, 2020).

[33] von Elm E, Altman DG, Egger M, Pocock SJ, Gøtzsche PC, Vandenbroucke JP. The strengthening the reporting of observational studies in epidemiology (STROBE) statement: Guidelines for reporting observational studies. Int J Surg. 2014;12(2):1495-9. https://doi.org/10.1016/j. ijsu.2014.07.013.

[34] Spielberger CD, Gorsuch RL, Lushene RE. STAI manual for the state-trait anxiety inventory. Self-Evaluation Questionnaire. MANUAL 1970. https://doi.org/10.1037/t06496000 .

[35] Spielberger CD, Gorsuch RL, Lushene R. State-Trait Anxiety Inventory for Adults Sampler Set Manual, Instrument and Scoring Guide. Consult Psychol Press Inc Mind Gard Inc. 1983. https://doi.org/10.1037/t06496-000.

[36] Öner N, LeCompte WA. Durumluk-sürekli kaygıenvanteri el kitabı. İstanbul: Boğaziçi Üniversitesi yayınları; 1983.

[37] Erçetin SS, Potas N, Açıkalın SN, Sarinç Ulaşlı S, Çevik MS, Görgülü D, et al. The Effect of COVID-19 Pandemic on Quality of Life: March 30 - April 05, 2020 (Cases of Ístanbul, Ankara, Konya Provinces). vol. 1. 2020.

[38] Young SN. The neurobiology of human social behaviour: An important but neglected topic. J Psychiatry Neurosci. 2008;33(5):391-2.

[39] Freeman R, Maguire A, Ryan V, Wilson N, Innes NPT, Clarkson JE, et al. The FiCTION trial: Child oral healthrelated quality of life and dental anxiety across three treatment strategies for managing caries in young children. Community Dent Oral Epidemiol. 2020;48(4):328-37. https://doi.org/10.1111/cdoe.12537.

[40] Gendlin ET. A theory of personality change. New Dir ClientCentered Ther. 1970.

[41] Oreg S. Personality, context, and resistance to organizational change. Eur J Work Organ Psychol. 2006;15(1):73-101. https://doi.org/10.1080/13594320500451247.

[42] Jung HS, Baek E. A structural equation model analysis of the effects of emotional labor and job stress on depression among nurses with long working hours: Focusing on the mediating effects of resilience and social support. Work. 2020;66(3):561-8. https://doi.org/10.3233/WOR-203198.

[43] Danesh MK, Garosi E, Mazloumi A, Najafi S. Identifying factors influencing cardiac care nurses' work ability within the framework of system engineering initiative for patient safety. Work. 2020;66:569-77. https://doi.org/ 10.3233/WOR-203199. 